\title{
The Electrocatalysis of Multi-walled Carbon Nanotubes (MWCNTs) for Oxygen Reduction Reaction (ORR) in Room Temperature Ionic Liquids (RTILs)
}

\author{
Keqiang Ding* \\ College of Chemistry and Materials Science, Hebei Normal University, \\ Shijiazhuang 050016, P. R. China
}

Received 17 October 2008; accepted 23 February 2009

\begin{abstract}
Oxygen reduction reaction (ORR) was investigated on a multi-walled carbon nanotubes (MWCNTs)-modified edge plane pyrolytic graphite (EPPG) electrode using cyclic voltammetry $(\mathrm{CV})$ in three kinds of room temperature ionic liquids (RTILs), i.e., 1ethyl-3-methylimidazolium tetrafluoroborate $\left(\mathrm{EMIBF}_{4}\right)$, 1-n-propyl-3-methylimidazolium tetrafluoroborate $\left(\mathrm{PMIBF}_{4}\right)$, and 1- $n$-butyl-3-methylimidazolium tetrafluoroborate $\left(\mathrm{BMIBF}_{4}\right)$. The results demonstrated that, after being modified by MWCNTs on the EPPG electrode, both the reduction peak current of oxygen and the oxidation peak current of superoxide anion were all dramatically increased, and the values of standard rate constant, $\kappa_{\mathrm{s}}$, corresponding to ORR, were greatly enhanced. Under the same condition, in $\mathrm{PMIBF}_{4}, \mathrm{MWCNTs}$-modified EPPG electrode exhibited the most satisfied electrocatalysis for ORR, in which standard rate constant, $\kappa_{\mathrm{s}}$, was improved from $2.9 \times$ $10^{-3} \mathrm{~cm} \mathrm{~s}^{-1}$ on a EPPG electrode, to $10.4 \times 10^{-3} \mathrm{~cm} \mathrm{~s}^{-1}$. While in $\mathrm{EMIBF}_{4}$ and $\mathrm{BMIBF}_{4}$, after being modified by MWCNTs, the value of $\kappa_{\mathrm{s}}$ was increased from $4.3 \times 10^{-3}$ to 8.3 $\times 10^{-3}$ and $2.3 \times 10^{-3}$ to $4.2 \times 10^{-3} \mathrm{~cm} \mathrm{~s}^{-1}$, respectively. For the catalysis of MWCNTsmodified EPPG electrode towards ORR, the enhanced surface area of electrode and the increased amount of "defect" sites on electrode were thought to be the main reasons for our obtained results.
\end{abstract}

Keywords: multi-walled carbon nanotubes (MWCNTs), room temperature ionic liquids (RTILs), oxygen reduction reaction (ORR), graphite electrode.

\footnotetext{
"Corresponding author. E-mail address: dkeqiang@263.net
} 


\section{Introduction}

As a novel kind of media between water phase and organic phase, room temperature ionic liquids (RTILs) have attracted much more attentions. Many features of RTILs, for example, low-volatility, non-oxicity, nonflame, high conductivity compared to the commonly used organic solvents, and higher solubility for organic substances have been presented [1-4]. Although, there are numerous papers concerning RTILs published every year, to the best of our knowledge, the application of RTILs in large scale was poorly reported, i.e., the magnificent application of RTILs still remains raveled.

Researching oxygen reduction reaction (ORR) at least has two widely accepted meanings. As a half reaction happening at cathode in fuel battery, clarifying the mechanism of ORR is helpful to improve the capability of fuel cells [5]. The other one is that one reduction product of oxygen, i.e., superoxide anion $\mathrm{O}_{2}{ }^{-}$, was reported to be closely involved in the etiology of aging, cancer, and progressive neurodegenerative diseases such as Parkinson's disease[6,7,], thus, sufficiently comprehending the behavior of superoxide anion, $\mathrm{O}_{2}^{-}$, is beneficial for unveiling the mechanism of molecular oxygen cycle in human body. Research of ORR in aproton organic solvent and aqueous solution has been well reported [8-13].

Due to lacking protons, RTILs was selected as a kind of benign electrolyte in which ORR was well probed by Osteryoung and Alnashef [14, 15]. They have verified the existing of superoxide anion, $\mathrm{O}_{2}^{-}$, produced from ORR, in RTILs. The influence of both electrode and RTILs on ORR has also been discussed systematically [16], in which the glassy carbon (GC), platinum (Pt) and gold (Au) electrodes were used. As reported previously, pyrolytic graphite electrodes were usually grouped as the basal plane pyrolytic graphite (BPPG) electrode, containing all atoms of a particular graphite layer, and the edge plane pyrolytic graphite (EPPG) electrode, perpendicular to the basal plane [17]. Generally speaking, edge plane pyrolytic graphite (EPPG) electrodes are advantageous when used as electrode substrates in electroanalysis due to the highly reactive edge plane sites which allow low detection limits, high sensitivities, improved signal to noise characteristics and low overpotentials[18]. In this work, an edge plane pyrolytic graphite (EPPG) electrode was employed, in which the kinds of RTILs used were identical to those used in previous reports [16].

Carbon nanotubes (CNTs), classified as multi-walled carbon nanotubes (MWCNTs) and single-walled carbon nanotubes (SWCNTs), have cylindrical graphite sheets with nanometer diameter and behave like metallic or semiconducting wires. CNTs have been thought as attractive material in biochemical sensing system for immobilizing biomolecules (proteins or enzymes) and facilitating the electron transfer process occurring between the huge biomolecules and electrode [19, 20]. Accordingly, CNTs have been employed as a useful material to modify electrode surface in order to enlarge the electrochemical response [21].

To our knowledge, higher viscosity of RTILs has resulted in the lowered diffusion coefficient of substance in RTILs [22] limiting the application of RTILs not only in organic synthesis but also in electrochemistry; to overcome this flaw, 
in this work, we introduced MWCNTs onto an EPPG electrode to acquire a promoted response of ORR.

Based on our previous work [23], the electrocatalysis of MWCNTs for ORR in RTILs was discussed in the present work. Results revealed that in three kinds of RTILs, after being modified by MWCNTs, the electrochemical reduction current of oxygen, and electrochemical oxidation current of superoxide anion as well, were all dramatically increased. Meanwhile, the enhanced $\kappa_{\mathrm{s}}$ were all observed in RTILs, indicating that MWCNTs still kept its catalysis for ORR in RTILs, consistent with the results obtained in aqueous solution.

\section{Experimental}

\section{Reagents and materials}

Multi-walled carbon nanotubes (MWCNTs, outer diameter: 60-100nm, inner diameter: $5-10 \mathrm{~nm}$, length: 0.5-500 $\mu \mathrm{m})$ were purchased from Shenzhen Nanotech Port Co., Ltd. RTILs with a purity of more than $99 \%$ were obtained from Hangzhou Chemer Chemical CO., Ltd (China). The molecular structures of RTILs are shown in Scheme 1. EPPG $(\varnothing=2 \mathrm{~mm})$ electrode purchased from Tianjin Aida Co., Ltd (China) was used as the working electrode.

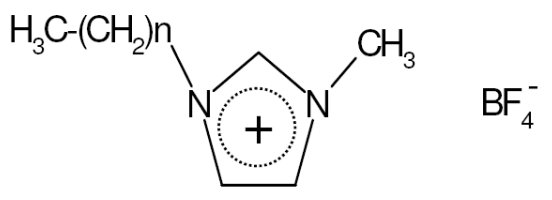

$(n=1,2,3)$

Scheme 1. Structural frame of the room-temperature ionic liquids used.

\section{Apparatus and procedures}

Cyclic voltammetry was performed using a potentiostat/galvanostat (EG\&G, Princeton Applied Research) that contains a software of model 273 [24] in a home-made three-electrode one-compartment electrochemical cell. A Pt spiral wire was employed as the auxiliary electrode and a silver chloride coated-Ag wire ( denoted as solid $\mathrm{Ag} / \mathrm{AgCl}$ ) as the reference electrode.

The working electrode, i.e., edge plane pyrolytic graphite (EPPG) electrode, was successively polished with 1 and $0.06 \mu \mathrm{m}$ alumina powder on micro-cloth wetted with Milli-Q water before use. And then the electrodes were carefully sonicated in Milli-Q water for 10 min and rinsed with Milli-Q water. Finally the electrode was electrochemically cleaned by repeating the potential between -0.9 and $1.6 \mathrm{~V}$ vs. $\mathrm{Ag} / \mathrm{AgCl}, \mathrm{KCl}$-sat reference electrode at a scan rate of $0.1 \mathrm{~V} / \mathrm{s}$ in $0.05 \mathrm{M}$ $\mathrm{H}_{2} \mathrm{SO}_{4}$ solution until steady-state $\mathrm{CV}$ response was obtained. The pretreated electrodes were well dried with hot air to avoid bringing any water into ionic liquid system. For degassing oxygen, $\mathrm{N}_{2}$ was bubbled into the used ionic liquids for $30 \mathrm{~min}$, and $\mathrm{O}_{2}$ gas was bubbled directly into the cell at least for $30 \mathrm{~min}$ to gain the $\mathrm{O}_{2}$-saturated ionic liquids. All the electrochemical experiments were conducted at ambient temperature $(25 \pm 1)^{\circ} \mathrm{C}$. 


\section{Preparation of MWCNTs-modified electrode}

MWCNTs-Nafion suspension was prepared by dispersing MWCNTs into alcohol solution containing $0.05 \%$ Nafion, by ultrasonication agitation for about $15 \mathrm{~min}$ to form a solution in which the content of MWCNTs is about $1 \mathrm{mg} / \mathrm{mL}$. The surface of the EPPG electrode was modified by $5 \mu \mathrm{L}$ of the MWCNTs-Nafion suspension by droplet and treated to evaporate the solvent at room temperature for $30 \mathrm{~min}$ [21]; before transferring into RTILs, MWCNTs-modified EPPG was dried again to guarantee being free of water and alcohol solution, which was denoted as MWCNTs-modified EPPG, while the Nafion film-modified EPPG was prepared by the same process with only $0.05 \%$ Nafion alcohol solution.

\section{Results and discussion}

\section{Cyclic voltammetry of the $\mathrm{O}_{2} / \mathrm{O}_{2}^{-}$redox couple on EPPG electrode in RTILs}

Fig. 1 shows the typical cyclic voltammograms (CVs) of ORR in $\mathrm{EMIBF}_{4}$ on a bare EPPG electrode. At the scan rate of $100 \mathrm{mV} \mathrm{s}^{-1}$, the peak potential separation, $\Delta E_{\mathrm{p}},\left(\Delta E_{\mathrm{p}}=E_{\mathrm{pa}}-E_{\mathrm{pc}}\right.$, in which $E_{\mathrm{pa}}$ and $E_{\mathrm{pc}}$ are the anode peak potential and the cathode peak potential, respectively.), is $152 \mathrm{mV}$ instead of $60 \mathrm{mV}$, and the ratio of oxidation peak current to reduction peak current was 0.52 rather than unit, demonstrating that a well-defined quasi-reversible reaction was observed, consistent with the previous results [16] very well. The well-defined linear relation between square root of scan rate and the reduction peak current, as shown by the inset in Fig. 1, allows us to evaluate the standard rate constant, $\kappa_{\mathrm{s}}$, using the formula derived by Nicholson [25]. Here, in $\mathrm{EMIBF}_{4}, \kappa_{\mathrm{s}}$ was estimated to be about $4.3 \times 10^{-3} \mathrm{~cm} \mathrm{~s}^{-1}$, close to the former reported data [16] obtained on a glassy carbon (GC) electrode, in which $\kappa_{\mathrm{s}}$ was estimated to be about $6.4 \times 10^{-3} \mathrm{~cm}$ $\mathrm{s}^{-1}$ by normal pulse voltammetry.

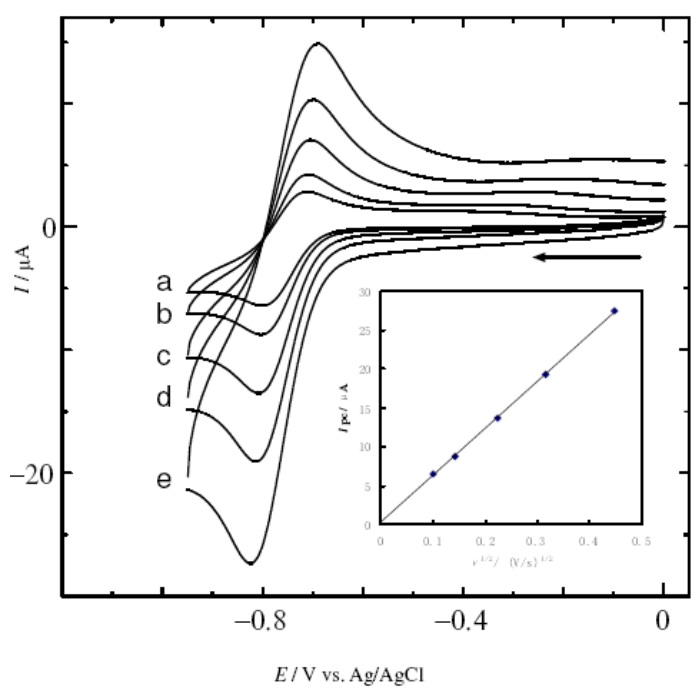

Figure 1. CVs obtained on a bare EPPG electrode in $\mathrm{O}_{2}$-saturated $\mathrm{EMIBF}_{4}$. Scan rates: (a) 10, (b) 20, (c) 50, (d) 100, and (e) $200 \mathrm{mV} / \mathrm{s}$.

Using the same method, the values of $\kappa_{\mathrm{s}}$ corresponding to ORR on the bare EPPG electrode in $\mathrm{PMIBF}_{4}$ and $\mathrm{BMIBF}_{4}$ were estimated to be about $2.9 \times 10^{-3} \mathrm{~cm} \mathrm{~s}^{-1}$ and 
$2.3 \times 10^{-3} \mathrm{~cm} \mathrm{~s}^{-1}$, respectively. As reported [16], the kinematic viscosity of $\mathrm{BMIBF}_{4}$ is $1.49 \mathrm{~cm}^{2} \mathrm{~s}^{-1}$, while in the case of EMIBF 4 and $\mathrm{PMIBF}_{4}$ they are 0.289 and $0.831 \mathrm{~cm}^{2} \mathrm{~s}^{-1}$, respectively. Besides, diffusion coefficient $\mathrm{D}$ is inversely proportional to kinematic viscosity, as described by the formula, $\mathrm{D}=\left(\kappa_{\mathrm{B}} T\right) /$ $\left(\mathrm{c} \pi \eta r_{s}\right)$ [26], where $\kappa_{\mathrm{B}}$ is the Boltzmann constant $\left(1.3806 \times 10^{-23} \mathrm{~J} \mathrm{~K}^{-1}\right)$, c is a constant ( 4 and 6 for the slip and stick boundary conditions, respectively), $\eta$ is the solvent viscosity, and $r_{s}$ is the radius of the diffusion molecule modeled as a sphere. Also, generally, the larger value of $\mathrm{D}$ corresponds to a higher standard rate constant [27], therefore, the higher viscosity of $\mathrm{BMIBF}_{4}$ should account for the lower value of $\kappa_{\mathrm{s}}$ of ORR in $\mathrm{BMIBF}_{4}$.

\section{Electrochemical behavior of oxygen on MWCNTs-modified EPPG electrode in RTILs}

In aqueous solution, as well as in organic systems, carbon nanotubes (CNTs) have been reported to be able to accelerate the electron transfer process happening at the interface of electrolyte/electrode [20]. However, in RTILs, the electrocatalysis of CNTs were poorly discussed [19, 23], which intrigued us to carry out the investigation of CNTs in RTILs. In addition, the quasi-reversible reaction of ORR in RTILs on the EPPG electrode also allowed us to improve the electron transfer process of ORR in RTILs. To accelerate the electron transfer process occurring at electrode/RTILs interface, here one kind of CNTs, MWCNTs was immobilized on the surface of EPPG electrode with an intention to improve the response of ORR in RTILs.

From Fig. 2A, it can be seen that both the reduction peak current of oxygen and the oxidation peak current of superoxide anion, $\mathrm{O}_{2}^{-}$, were all dramatically increased when MWCNTs was modified on a bare EPPG electrode. For example, in $\mathrm{EMIBF}_{4}$, the reduction peak current of oxygen was promoted from $21.0 \mu \mathrm{A}$ obtained on a bare EPPG electrode to $30.7 \mu \mathrm{A}$ when EPPG electrode was immobilized by MWCNTs. The dashed line in Fig. 2A is CVs of ORR on the Nafion film-modified EPPG electrode, and the slightly attenuated peak current demonstrated that the effect of Nafion film on ORR could be ignored, allowing us to continue the following work. Encouragingly, the increased peak currents were all observed in the other two kinds of RTILs, i.e., $\mathrm{PMIBF}_{4}$ and $\mathrm{BMIBF}_{4}$, as shown by Fig. 2B and Fig. 2C, respectively.

For the MWCNTs-modified EPPG electrode, the influence of scan rate on CVs of ORR in $\mathrm{EMIBF}_{4}$ is clearly illustrated by Fig. 3. The well-defined linear relationship between square root of scan rate and the reduction peak current was also observed as shown by the inset in Fig. 3. Hence, for the diffusion-controlled process, we can evaluate the value of $\kappa_{\mathrm{s}}$ using the same formula as stated above [25], where the value of $\kappa_{\mathrm{s}}$ for ORR in $\mathrm{EMIBF}_{4}$, was enhanced from $4.3 \times 10^{-3} \mathrm{~cm}$ $\mathrm{s}^{-1}$ obtained on a bare EPPG electrode, to $8.3 \times 10^{-3} \mathrm{~cm} \mathrm{~s}^{-1}$ when MWCNTs were modified on the EPPG. electrode. For ORR, the linear relations between the square root of scan rate and reduction peak current were all observed in $\mathrm{PMIBF}_{4}$ and $\mathrm{BMIBF}_{4}$, and the values of $\kappa_{\mathrm{s}}$ obtained on the MWCNTs-modified EPPG electrode in $\mathrm{PMIBF}_{4}$ and $\mathrm{BMIBF}_{4}$ were estimated to be about $10.4 \times 10^{-3} \mathrm{~cm} \mathrm{~s}^{-1}$ and $4.2 \times 10^{-3} \mathrm{~cm} \mathrm{~s}^{-1}$, respectively. 

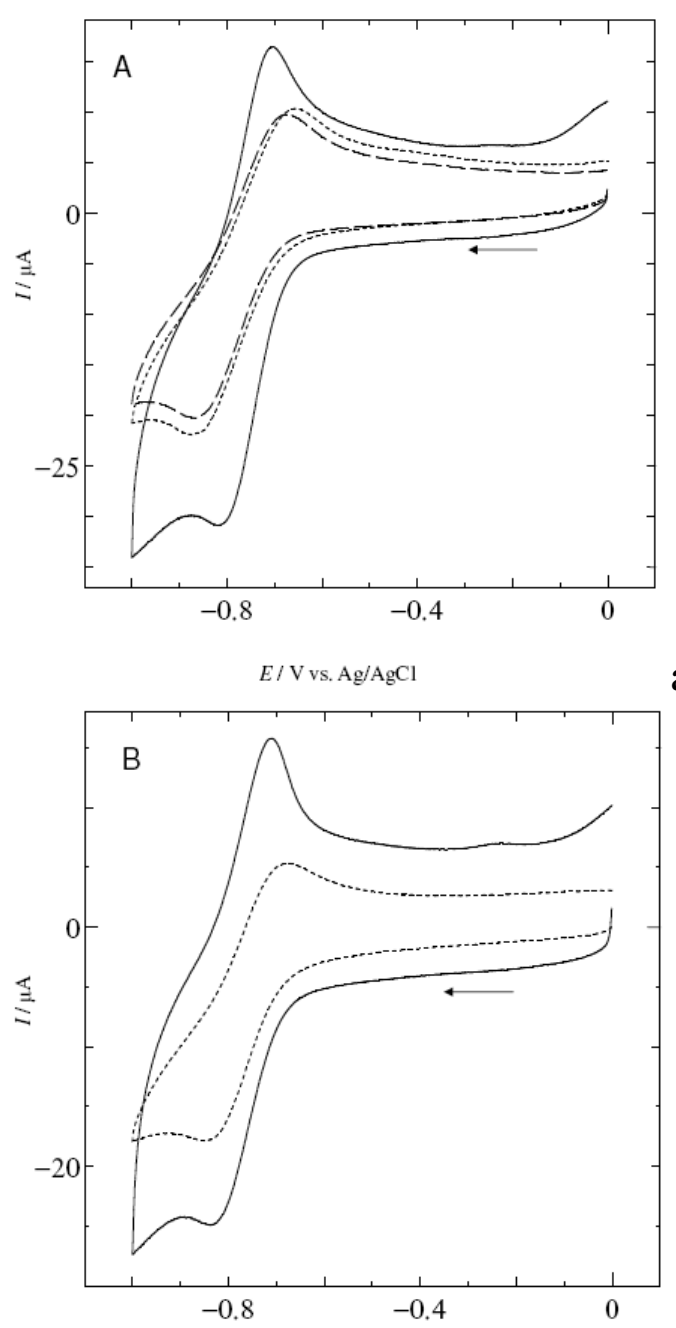

a)

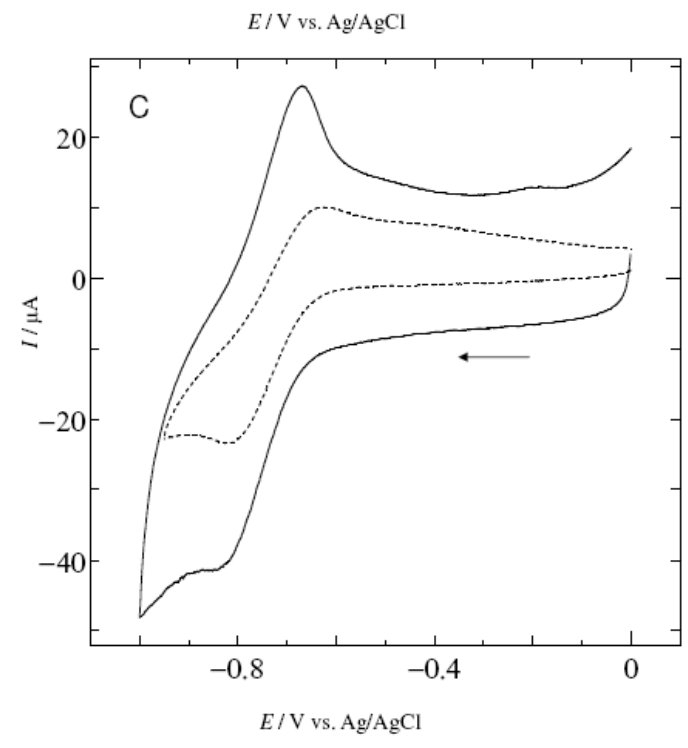

b)

c)

Figure 2. $\mathrm{CV}$ s obtained in $\mathrm{O}_{2}$-saturated (a) $\mathrm{EMIBF}_{4}$, (b) $\mathrm{PMIBF}_{4}$ and (c) $\mathrm{BMIBF}_{4}$. Dashed line (a): obtained on a Nafion film-modified EPPG electrode; dotted line: obtained on a bare EPPG electrode; solid line: obtained on a MWCNTs-modified EPPG electrode. Scan rate: $100 \mathrm{mV} / \mathrm{s}$. 


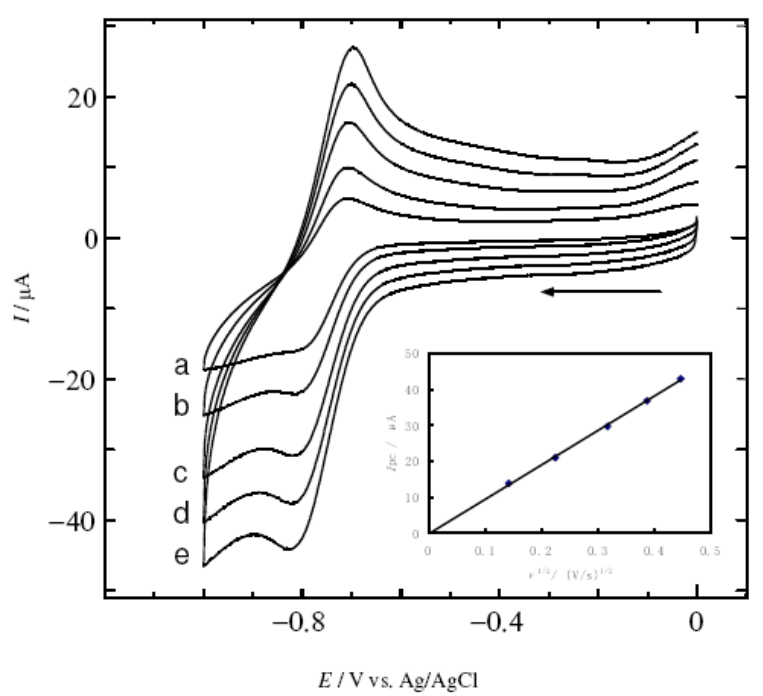

Figure 3. CVs obtained on a MWCNTs-modified EPPG electrode in $\mathrm{O}_{2}$-saturated EMIBF$_{4}$. Scan rates: (a) 20, (b) 50, (c) 100, (d) 150, and (e) $200 \mathrm{mV} / \mathrm{s}$.

To quote the formal potential $\left(E^{0 \prime}\right)$ of the $\mathrm{O}_{2} / \mathrm{O}_{2}^{-}$redox couple with respect to that of the ferricenium/ferrocene $\left(\mathrm{Fc}^{+} / \mathrm{Fc}\right)$ redox couple, $\mathrm{CVs}$ of the $\mathrm{Fc}^{+} / \mathrm{Fc}$ redox couple in RTILs were recorded. The values of $E^{0 \prime}$ corresponding to the redox of $\mathrm{Fc}^{+} / \mathrm{Fc}$ in $\mathrm{EMIBF}_{4}, \mathrm{PMIBF}_{4}$ and $\mathrm{BMIBF}_{4}$ were estimated to be about $0.23,0.23$ and $0.26 \mathrm{~V} v s$. solid $\mathrm{Ag} / \mathrm{AgCl}$ reference electrode, respectively. In principle, for the well-defined one-electron reversible reaction, the peak potential separation, $\Delta E_{\mathrm{p}}$, should be about $59 \mathrm{mV}$, but for our case, on the bare EPPG electrode, at the scan rate of $20 \mathrm{mV} / \mathrm{s}$, the value of $\Delta E_{\mathrm{p}}$ was $67 \mathrm{mV}$, and as the scan rate increased, $\Delta E_{\mathrm{p}}$ was also enhanced. Our result is similar to the former report [18], in which on a EPPG electrode in $0.1 \mathrm{M} \mathrm{KCl}$, at the scan rate of $100 \mathrm{mV} / \mathrm{s}, \Delta E_{\mathrm{p}}$ for the redox of ferricyanide was found to be $78 \mathrm{mV}$. To take a direct insight into the influence of MWCNTs on the redox couple of $\mathrm{Fc}^{+} / \mathrm{Fc}$, typical CVs for the redox couple of $\mathrm{Fc}^{+} / \mathrm{Fc}$ at a scan rate of $20 \mathrm{mV} / \mathrm{s}$ on different electrodes were drawn in Fig. 4, from which we know, after being modified by Nafion film, the value of $\Delta E_{\mathrm{p}}$ was increased to $71 \mathrm{mV}$, and the peak current was slightly attenuated. However, after being modified by MWCNTs, at the scan rate of $20 \mathrm{mV} / \mathrm{s}, \Delta E_{\mathrm{p}}$ was decreased from $67 \mathrm{mV}$ exhibited on the bare EPPG electrode to $61 \mathrm{mV}$, and instead, the reduction peak current was increased from $1.0 \mu \mathrm{A}$ to $1.4 \mu \mathrm{A}$, suggesting that the immobilization of MWCNTs has accelerated the electron transfer process, not only according with the results obtained from Fig. 2A, 2B and $2 \mathrm{C}$, but also being consistent with the former proposition obtained in aqueous solution [18].

Fig. 5 clearly depicts the dependence of square root of scan rate on peak current, obtained from $\mathrm{CVs}$ of $\mathrm{Fc}^{+} / \mathrm{Fc}$ in $\mathrm{EMIBF}_{4}$ on different electrodes, where line $\boldsymbol{c}$ corresponds to the CVs obtained on a MWCNTs-modified EPPG electrode, and line $\boldsymbol{a}$ and line $\boldsymbol{b}$ stand for CVs measured on the bare EPPG electrode and Nafion film-modified EPPG electrode, respectively. No evident influence of modified Nafion film on CVs of Fc was illustrated through comparing the slope of line $a$ with that of line $\boldsymbol{b}$. While for the MWCNTs-modified EPPG electrode, except for the dramatically increased peak current, the slope of line $\boldsymbol{c}$ and line $c^{\prime}$ becomes 
steeper compared to that of the line $\boldsymbol{a}$ and line $\boldsymbol{a}$; for instance, the slope of line $\boldsymbol{a}$ is about $6.4 \mu \mathrm{A} /(\mathrm{V} / \mathrm{s})^{1 / 2}$, while for MWCNTs-modified EPPG, the slope was increased to about $12.1 \mu \mathrm{A} /(\mathrm{V} / \mathrm{s})^{1 / 2}$. Based on the previous formula, i.e., $I_{\mathrm{pa}}=$ $\left(2.69 \times 10^{5}\right) n^{3 / 2} A D_{\mathrm{Fc}}^{1 / 2} C_{\mathrm{Fc}} v^{1 / 2}$ (at $25^{\circ} \mathrm{C}$ ) [28], here the increased slope of line $c$ strongly demonstrated that MWCNTs has greatly increased the working electrode surface on the assumption that the value of diffusion coefficient $D_{\mathrm{Fc}}$ was not varied, but, the decreased $\Delta E_{\mathrm{p}}$ by the modification of MWCNTs, as shown in Fig.4, also indicated that the modification of MWCNTs on the EPPG electrode could not be thought as a simple "augmentation of electrode surface".

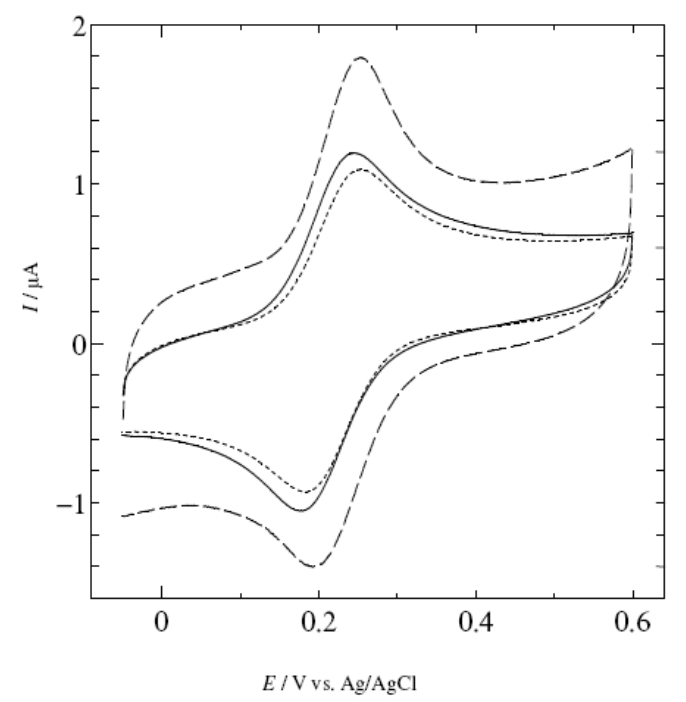

Figure 4. $\mathrm{CVs}$ of $\mathrm{EMIBF}_{4}$ containing $0.5 \mathrm{mM}$ Fc. Solid line: obtained on a bare EPPG electrode; dotted line: obtained on a Nafion film-modified EPPG electrode; dashed line: obtained on a MWCNTs-modified EPPG electrode. Scan rate: $20 \mathrm{mV} / \mathrm{s}$.

Based on the previous reports concerning MWCNTs, we know, there are many available explanations for its catalysis for the electrochemical process; for example, the modification of MWCNTs could augment the electrode surface [20], behaving like metallic conductor, allowing MWCNTs to increase the conductivity between the electrolyte and electrode [29], and so on.

But for our case, according to the former concrete description of MWCNTs [30], and combining with the fact that at the nanotube tips of MWCNTs, there are many pentagon-heptagon defect pairs in the lattice [8,31], that is to say, MWCNTs has numerous "defects". Thus, immobilizing MWCNTs on the electrode surface could create many "active points" on the electrode surface of EPPG and, as stated previously [8], the diameter of active points (with respect to the diffusion layer thickness) was decreased, the contribution of convergent diffusion to voltammetry increased such that faster mass transport per unit area of the electrode could result in larger current densities; subsequently, the increased peak current, and the promoted standard electron transfer rate as well, were all observed. Besides, we think, the introduction of RTILs has greatly altered the ion-atmosphere of molecular oxygen, which probably is favorable for molecular oxygen to interact with these "defects" on MWCNTs. Above reasons 
may be could account for our obtained results; more further and detailed research are under consideration.

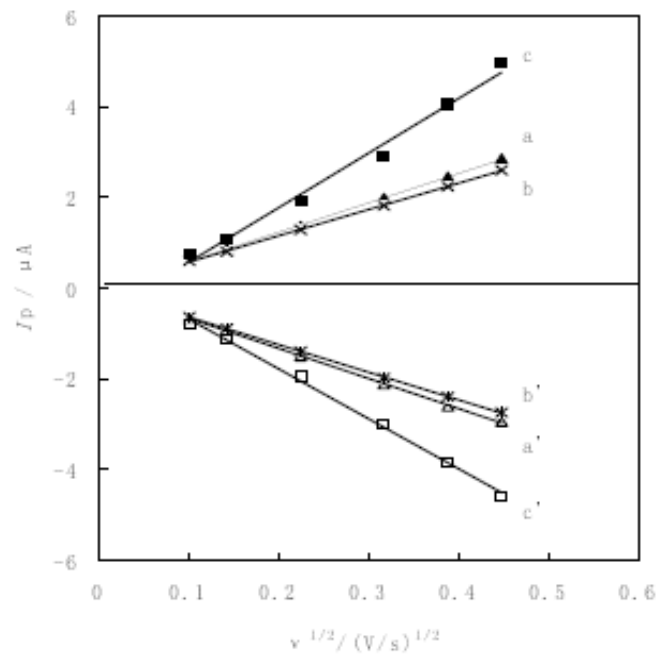

Figure 5. Dependence of peak current on the square root of scan rate. a, a': for the bare EPPG electrode, b, b': Nafion film-modified EPPG electrode; c, c': MWCNTs-modified EPPG electrode. a, b, c for the oxidation peak current, while a', b', c' for the reduction peak current. Data were adopted from CVs of $0.5 \mathrm{mM} \mathrm{Fc}$ in $\mathrm{EMIBF}_{4}$, and the positive peak current corresponds to the oxidation peak current, and negative value to the reduction peak current.

\section{Conclusions}

The electrocatalysis of MWCNTs, modified on a EPPG electrode, for ORR in three kinds of RTILs was clearly observed by CVs. After being modified with MWCNTs, both the reduction and oxidation currents were increased significantly compared to the results obtained on a bare EPPG electrode. The linear relationship between square root of scan rate and peak current allowed us to estimate the value of standard rate constant for ORR, and results demonstrated that after being modified by MWCNTs, in all three kinds of RTILs, the values of $\kappa_{\mathrm{s}}$ were all higher than that obtained on the bare EPPG electrode, suggesting that MWCNTs accelerated the electron transfer process happening at interface of RTILs/EPPG, and the maximum value of $\kappa^{0}$ was estimated to be about $10.4 \times 10^{-3}$ $\mathrm{cm} \mathrm{s}^{-1}$ in $\mathrm{PMIBF}_{4}$. Generating more "defects" on EPPG electrode by the immobilized MWCNTs was thought to be the main reason for our observed results. Further and detailed discussions are in progress.

\section{Acknowledgements}

This work was financially supported by the Doctor Fund of Hebei Normal University (L2003B10), Key Project of Hebei Province Education Bureau (ZH2007106), Key Project Fund of Hebei Normal University (L2008Z08) and Special Assist Project of Hebei Province Personnel Bureau(106115). 


\section{References}

1. T.Welton, Chem. Rev. 99 (1999) 2071.

2. R.M. Lau, F. Rantwijl, K.R. Seddon, R.A. Sheldon, Org. Lett. 2 (2000) 189.

3. M.P. Jensen, J.A. Dzielawa, P. Rickret, M.L. Dietz, J. Am. Chem. Soc. 124 (2002) 10664.

4. J.S. Lee, N.D. Quan, J.M. Hwang, J.Y. Bae, H. Kim, B.W. Cho, H.S. Kim, H. Lee, Electrochem. Commun. 8 (2006) 460.

5. $\quad$ N.K. Beck, B. Steiger, G.G. Scherer, A.Wokaun, Fuel Cells 6 (2006) 26.

6. A.Vanella, C. Di Giacomo, V. Sorrenti, A. Russo, C. Castorina, A. Campisi, M. Renis, J.R. Perez-Polo, Neurochem. Res. 18 (1993) 1337.

7. H.A. Kontos, E.P. Wei, J. Neurosurg. 64 (1986) 803.

8. Y. Che, M. Tsushima, F. Matsumoto, T. Okajima, K.Tokuda, T. Ohsaka, J. Phys. Chem. 100 (1996) 20134.

9. M.S. Saha, T. Ohsaka, Electrochim. Acta 50 (2005) 4746.

10. M.M. Islam, T. Okajima, T. Ohsaka, J. Phys. Chem. . 108 (2004) 19425.

11. J.F. Wu, Y. Che, T. Okajima, F. Matsumoto, K. Tokuda, T. Ohsaka, Electrochim. Acta 45 (1999) 987.

12. J.F. Wu, Y. Che, T. Okajima, F. Matsumoto, K. Tokuda, T. Ohsaka, Anal. Chem. 71 (1999) 4056.

13. F. Matsumoto, K. Tokuda, T. Ohsaka, Electroanalysis 8 (1996) 648.

14. M.T. Carter, C.L. Hussey, S.K.D. Strubinger, R.A. Osteryong, Inorg. Chem. 30 (1991) 1149.

15. I.M. Alnashef, M.L. Leonard, M.C. Kittle, M.A. Matthews, W. Weidner, Electrochem. Solid-State Lett. 4 (2001) D16.

16. D. Zhang, T. Okajima, F. Matsumoto, T. Ohsaka, J. Electrochem. Soc. 151 (2004) D31.

17. C.E. Banks, T.J. Davies, G.G. Wildgoose, R.G. Compton, Chem. Commun. 17 (2005) 829.

18. C.E. Banks, R.G. Compton, Anal. Sci. 21 (2005) 1263.

19. J.N. Barisci, G.G. Wallace, D.R. Macfarlane, R.H. Baughman, Electrochem. Commun. 6 (2004) 22.

20. J.S. Ye, Y. Wen, W.D. Zhang, L.M. Gan, G.Q. Xu, F.S. Sheu, Electrochem. Commun. 6 (2004) 66.

21. C. Hu, S. Yuan, S. Hu, Electrochim. Acta 51 (2006) 3013.

22. R.G. Evans, O.V. Klymenko, S.A. Saddoughi, C. Hardacre, R.G. Compton, J. Phys. Chem. B. 108 (2004) 7878.

23. K.Q. Ding, T. Okajima, T. Ohsaka, Electrochemistry 75 (2007) 35.

24. K.Q. Ding, Z. Jia, Q. Wang, X. He, N. Tian, R. Tong, X. Wang, J. Electroanal. Chem. 513 (2001) 67.

25. R.S. Nicholson, Anal. Chem. 37 (1965) 1351.

26. R.A. Robinson, R.H. Stokes, Electrolyte Solution, $2^{\text {nd }}$ ed., revised, Butterworths, London, 1959.

27. M. Matsumiya, M. Terazono, K. Tokuraku, Electrochim. Acta 51 (2006) 1178. 
28. A.J. Bard, L.R. Faulkner, Electrochemical Method, $2^{\text {nd }}$ ed., p. 231, John Wiley \& Sons, New York, 2001.

29. F. Zhao, X. Wu, M. Wang, Y. Liu, L.Gao, S. Dong, Anal. Chem. 76 (2004) 4960.

30. P.J. Britto, K.S.V. Santhanam, A. Rubio, J.A. Alonso, P.M. Ajayan, Adv. Mater. 11 (1999) 154.

31. V .H. Crespi, M.L. Cohen, A. Rubio, Phys. Rev. Lett. 79 (1997) 2093. 